Original Research Article

\title{
To evaluate the anticonvulsant activity of ethanolic extract of Moringa oleifera (drumstick leaves) in albino mice
}

\author{
Sushma V. Naidu, Harsha R.*, Jyothsnya S.
}

Department of Pharmacology, The Oxford Medical College, Hospital and Research Centre, Attibele Hobli, Anekal Taluk, Bangalore 562107, Karnataka, India

Received: 08 August 2017 Accepted: 01 September 2017

\author{
*Correspondence to: \\ Dr. Harsha R., \\ Email: harsha.ramakrishnaiah@ \\ gmail.com
}

Copyright: (C) the author(s), publisher and licensee Medip Academy. This is an openaccess article distributed under the terms of the Creative Commons Attribution NonCommercial License, which permits unrestricted noncommercial use, distribution, and reproduction in any medium, provided the original work is properly cited.

\begin{abstract}
Background: To evaluate the anti-convulsant activity of ethanolic extract of Moringa oleifera (Drum stick leaves) in seizure induced albino mice and to compare it with standard drug Sodium valproate.

Methods: Swiss albino mice of either sex weighing around $25-30 \mathrm{~g}$ were randomly selected and divided into four groups of six mice each. Group 1: control- treated with gum acacia. Group 2: Standard - Valproic acid 40mg/kg body weight. Group 3: T1- ethanolic extract of Moringa oleifera (150mg/kg). Group 4: T2 - ethanolic extract of Moringa oleifera $(300 \mathrm{mg} / \mathrm{kg})$. All drugs were administered orally one hour prior to induction of seizure. The anticonvulsant activity was screened using maximal electroshock seizure (MES) model and pentylenetetrazole (PTZ) model.

Results: Results were analysed by ANOVA followed by Bonferroni's post hoc test. Abolition of Tonic hind limb extension was taken as the protective end point against MES induced seizures and prolongation of seizure latency in PTZ model. At both the doses the ethanolic extract of Moringa oleifera significantly ( $p$ value $<0.05$ ) reduced the duration of hind limb extension in MES test and also significantly ( $p$ value $<0.05$ ) delayed the onset of clonic seizures in PTZ induced convulsion when compared with control group.

Conclusions: On comparing the percentage protection offered by Moringa oleifera leaves against both MES and PTZ model, it possesses significant anticonvulsant activity at both doses, with more efficacy at $300 \mathrm{mg} / \mathrm{kg} \mathrm{BW}$ indicating that the test drug can prove a very promising drug for treatment of epilepsy. Further studies are required for isolation and identification of the active constituent.
\end{abstract}

Keywords: Anti-convulsant, Moringa oleifera, MES, PTZ

\section{INTRODUCTION}

Epilepsy is one of the most common neurological disorders. India is home to about 10 million people with epilepsy. ${ }^{1}$ Epilepsy shows a prevalence rate of about $1-2 \%$ in world population. ${ }^{2}$ Epilepsy is a chronic disorder characterized by recurrent unprovoked seizure. An epileptic seizure refers to transient occurrence of signs and/or symptoms due to abnormal excessive (or) Synchronous neuronal activity in brain. ${ }^{3}$ Depending upon the distribution of discharge this abnormal CNS activity can have various manifestations ranging from convulsions to EEG changes. Etiology of epilepsy may vary from idiopathic to infection, neoplasm or trauma.

In spite of large number of drugs introduced for treatment of epilepsy, there is still a need for ideal antiepileptic drug as significant number of patients continue to have uncontrolled seizures either because they are not responsive to treatment or because of severe adverse effects associated with their use and also addiction liabilities upon long term use. As there is constant search 
for newer anti epileptic drugs with more efficacy and less adverse effects, attempts have been made in the past to screen anti convulsant compounds from plant origin phytomedicines which may provide ideas for developing newer antiepileptic drugs which can either be used alone or as adjuvant to the available anticonvulsant medications. $^{4}$

Moringa oleifera (MO) is a tree that grows widely in many tropical and subtropical countries. It is commonly known by the name Drumstick tree based on the appearance of its immature seed pods. ${ }^{5}$ Moringa oleifera is called miracle tree because of its high medicinal values. It has a wide range of medicinal use along with high nutritional value. MO is reported to contain alkaloids, flavanoids, anthocyanins, proanthocyanidins, cinnamates. ${ }^{6}$ Leaves also contain essential aminoacids, proteins, vitamin A, B, $\mathrm{C}$ and various minerals. ${ }^{7}$ A number of medicinal properties have been attributed to various parts of this tree. Almost all parts of this plant including root, bark, gum, leaf, fruit pods, flowers, seeds and seed oil have been used for various ailments in the indigenous medicines of south Asia. The various extract of leaves of Moringa oleifera are reported to have analgesic, anti-tumor, anti-ulcer, antipyretic, anti-spasmodic,antidiabetic, CNS depressant activities. Roots and bark of this plant are believed to have use in epilepsy and hysteria. ${ }^{8}$ It also acts as a good source of natural antioxidant due to the presence of various types of antioxidant compounds such as ascorbic acid, flavanoids, phenolics and carotenoids. Thus the present study deals with scientific validation of anti-convulsant potential of ethanolic extract of Moringa oleifera leaves in seizure induced albino mice.

\section{METHODS}

\section{Animals}

Albino mice of either sex weighing around 25-30g were randomly selected from central animal house facility. Animals were housed into group of six per cage at a temperature of $25^{\circ} \mathrm{C} \pm 1^{\circ} \mathrm{C}$ and relative humidity of 45 $55 \%$. Animals had limited access to food and water. The study protocol was approved by Institutional Animal Ethics Committee.

\section{Preparation of extract and isolation of active principle}

Moringa oleifera leaves were collected from local areas of Mysore, Karnataka. It was taken to JSS Ayurvedic College for authentication of plant and the species. After the plant and its leaves were identified and verified, the extract was prepared in JSS college of Pharmacy, Mysore. The leaves of Moringa oleifera were shade dried and grounded with the help of an electric grinder to get a free flowing powder. $100 \mathrm{~g}$ of leaves was extracted with $90 \%$ of ethanol in a Soxhlet apparatus for $24 \mathrm{hrs}$. Greenish extract was then evaporated under water bath to get thick mass and then air dried and kept in dessicator until further use.

\section{Drugs and chemicals}

- Valproic acid: $40 \mathrm{mg} / \mathrm{kg}$ body weight

- Pentylenetetrazole: $80 \mathrm{mg} / \mathrm{kg}$ body weight

- Ethanolic extract of Moringa oleifera: $150 \mathrm{mg} / \mathrm{kg}$ body weight, $300 \mathrm{mg} / \mathrm{kg}$ body weight

- Distilled water

- Gum acacia: used as suspending agent

\section{Methodology}

Animals were divided into four groups (with six mice in each group) for both the models - Maximal electro Shock (MES) induced seizure and Pentylene Tetrazole (PTZ) induced seizure models after overnight fasting.

- $\quad$ Group I: Received gum acacia and served as control (C)

- Group II: Received Sodium Valproate $(40 \mathrm{mg} / \mathrm{kg}$ body weight) and served as Standard group (S)

- Group III: Received Moringa oleifera extract of $150 \mathrm{mg} / \mathrm{kg}$ body weight and served as Test Group1 (T1)

- Group IV: Received Moringa oleifera extract $300 \mathrm{mg} / \mathrm{kg}$ body weight and served as Test Group 2 (T2).

All the drugs were administered orally 60 minutes prior to the test in this study.

\section{Assessment of anticonvulsant activity}

\section{Maximal electroschock induced seizures (MES MODEL)}

MES model was used to evaluate the anti convulsant activity of ethanolic extract of Moringa oleifera leaves. Swiss albino mice weighing $25-30 g$ were used. The animals were pre screened for their ability to develop full tonic extensions in the maximal electroschock test and only those which showed good response were included in the test. Electrical stimulation causes seizures which passes through the phases of tonic limb extension; tonic limb flexion, clonus period. The electrical stimulus was applied through ear clip electrodes using an electro convulsiometer 60 minutes after the administration of standard drug and plant extract. Suppression of tonic hind limb extension was considered as a protective measure against MES induced seizures.

\section{Pentylenetetrazole (PTZ) induced seizures}

Pentylenetetrazole is a central nervous system stimulant. The convulsant effect is analogue to petitmal type of convulsions in man. Seizures were induced in mice with Pentylenetetrazole at a dose of $80 \mathrm{mg} / \mathrm{kg}$ body weight given intraperitonally. The animals were observed for onset of convulsions till 30 minutes after administration of pentylenetetrazole. The efficacy of test drug was assessed by its ability to prolong onset of clonic seizure. 


\section{RESULTS}

\section{MES Model}

Ethanolic extract of Moringa oleifera produced significant dose dependent antiepileptic activity in comparison with control group. The extract at dose of $300 \mathrm{mg} / \mathrm{kg}$ produced marked reduction in duration of Tonic hind limb extension $(5.03 \pm 1.51 \mathrm{~s})$ in comparison to dose of $150 \mathrm{mg} / \mathrm{kg}$ $(7.93 \pm 0.96 \mathrm{~s})$. The mean duration of Tonic hind limb extension is shown in Table 1 along with other parameters of MES Model. It was also noted that clonus period was also reduced in Moringa oleifera treated group to $12.08 \pm 1.40 \mathrm{~s}$ when compared to control group $16.73 \pm 1.23$. The percentage protection of MO against THLE showed T1 $14.37 \%$ and T2 $45.69 \%$ compared to control showing that $\mathrm{T} 2(300 \mathrm{mg} / \mathrm{kg} \mathrm{BW})$ has better efficacy compared to T1 (150 mg/kg BW).

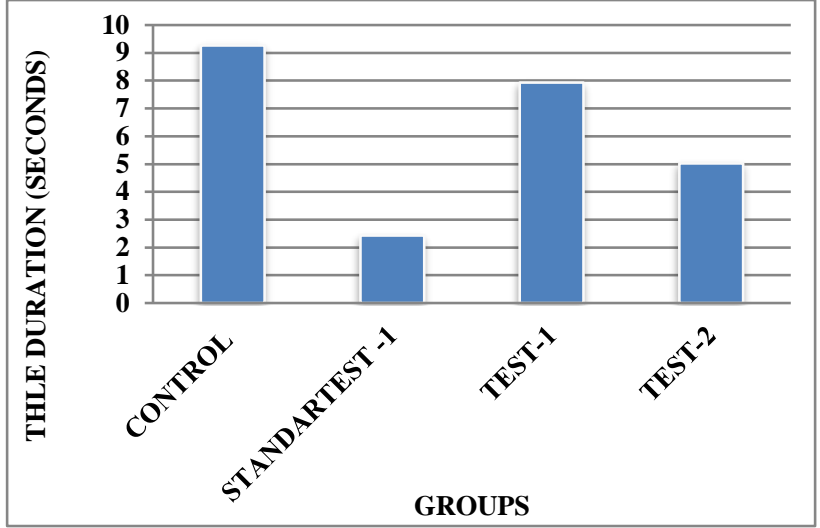

Figure 1: Effect of ethanolic extract of Moringa oleifera on Tonic hind limb extension phase (THLE) in MES model. Comparison of mean duration (in seconds).

Table 1: Comparison of mean duration (in seconds) and standard deviation values of different parameters in MES model.

\begin{tabular}{|lllll|}
\hline Parameter & Control & Standard & Test group 1 (T1) & Test group 2 (T2) \\
\hline Tonic hind limb flexion (THLF) & $7.93 \pm 1.05$ & $4.30 \pm 0.715$ & $7.3 \pm 1.32$ & $7.21 \pm 0.75$ \\
\hline Tonic hind limb extension (THLE) & $9.26 \pm 1.12$ & $2.43 \pm 0.73$ & $7.93 \pm 0.96$ & $5.03 \pm 1.51$ \\
\hline Clonus & $16.73 \pm 1.23$ & $11.46 \pm 0.88$ & $14.21 \pm 2.59$ & $12.08 \pm 1.40$ \\
\hline Stupor & $293.66 \pm 21.19$ & $112.16 \pm 11.12$ & $216.66 \pm 19.85$ & $155.56 \pm 25.79$ \\
\hline Post ictal Depression (PID) & $392.16 \pm 50.70$ & $125 \pm 6.03$ & $284.16 \pm 38.41$ & $283.66 \pm 21.91$ \\
\hline *values are expressed as mean \pm SD. Statistical analysis of data are carried out by one way ANOVA followed by post hoc Bonferronis \\
$\begin{array}{l}\text { Multiple Comparison tests. } \\
* \text { p value }<0.05 \text { is significant }\end{array}$
\end{tabular}

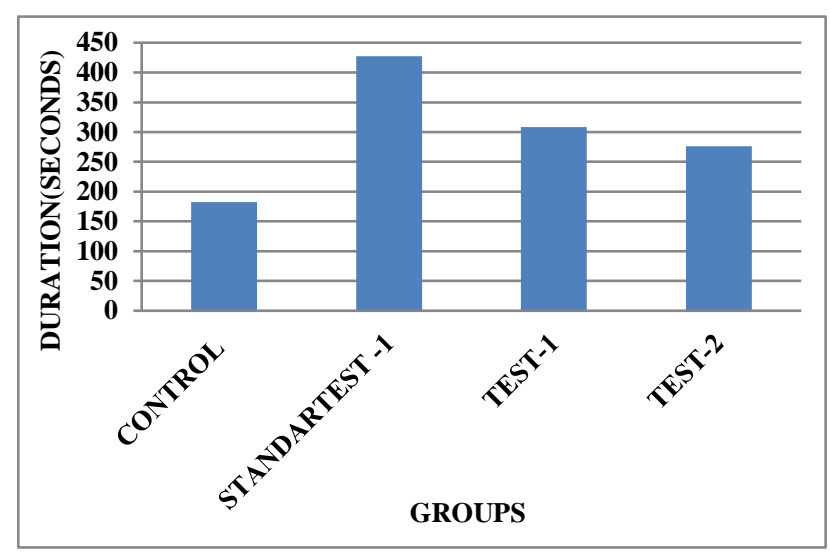

Figure 2: Effect of ethanolic extract of Moringa Oleifera on seizure latency in PTZ Model.

\section{PTZ Induced seizure}

The seizure latency produced by the test drug at a dose $300 \mathrm{mg} / \mathrm{kg}$ (T2) is $276.50 \pm 62.15 \mathrm{~s}$ in comparison to dose of $150 \mathrm{mg} / \mathrm{kg}$ (T1) $308.50 \pm 48.38 \mathrm{~s}$. The mean duration of seizure latency is shown in Table 3 along with other parameters of PTZ model. The percentage protection from seizure by $\mathrm{T} 1$ was $59.01 \%$ and $\mathrm{T} 2$ was $65.94 \%$ proving that the drug has better efficacy in controlling PTZ induced siezures.

Table 2: Percentage of inhibition conferred by (with respect to Tonic Hind Limb Extension) different groups in Maximum Electroshock Seizure (MES) method.

\begin{tabular}{|ll|}
\hline Group & $\%$ Protection \\
\hline Control & 0 \\
\hline Standard & $73.76 \%$ \\
\hline Test Group (T1) & $14.37 \%$ \\
\hline Test Group (T2) & 45.69 \\
\hline
\end{tabular}

\section{DISCUSSION}

Epilepsy is a major public health issue in many countries. Epilepsy affects $0.5-1 \%$ of world population. Incidence in India is around 20-50 cases per lakh population. ${ }^{9}$ Due to heterogeneity of the disease, the development of antiepileptic drugs has been a challenging task. Although newer and selective agents have been developed, there is still a drawback due to their side effect profile and also few 
cases being refractory to conventional treatment. So, the current study was undertaken to evaluate the anticonvulsant activity of ethanolic extract of Moringa oleifera at two different doses $150 \mathrm{mg} / \mathrm{kg}$ and $300 \mathrm{mg} / \mathrm{kg}$ in Maximum electroshock model (MES) and Pentylenetetrazole (PTZ) models.

Table 3: Comparison of Mean duration (in seconds) and SD values of different parameters in PTZ model $($ Mean \pm SD).

\begin{tabular}{|lllll|}
\hline Parameters & Control & Standard & Test group 1 & Test group 2 \\
\hline Seizure latency & $182.50 \pm 34.68$ & $427.16 \pm 43.64$ & $308.50 \pm 48.38$ & $276.50 \pm 62.15$ \\
\hline Myoclonic Jerks & $5.71 \pm 0.72$ & $2.18 \pm 0.72$ & $6.08 \pm 0.84$ & $3.71 \pm 1.04$ \\
\hline Generalized clonic seizure & $11.76 \pm 1.00$ & $6.01 \pm 0.68$ & $8.76 \pm 0.68$ & $8.35 \pm 1.08$ \\
\hline Post Ictal depression & $324.16 \pm 39.29$ & $165.50 \pm 54.33$ & $300.50 \pm 62.16$ & $276.33 \pm 42.03$ \\
\hline
\end{tabular}

*values are expressed as mean \pm SD. Data was analysed by one way ANOVA followed by post hoc test. P value $<0.05$ when compared with Control Group

Table 4: Percentage protection in seizure latency among various groups in PTZ Model compared to standard.

\begin{tabular}{|ll|}
\hline Group & Protection $(\%)$ \\
\hline Control & $42.62 \%$ \\
\hline Standard & $100 \%$ \\
\hline Test group 1(T1) & $59.01 \%$ \\
\hline Test group 2(T2) & $65.94 \%$ \\
\hline
\end{tabular}

MES model and PTZ models are the most common and predictive tests for screening of anticonvulsant activity in animal models. MES model predicts activity against generalized tonic clonic seizure and cortical focal seizure. MES model does not give any clue regarding the mechanism of action of compound. While PTZ tests activity against petitmal epilepsy or absence seizures. PTZ acts as a convulsant by antagonizing the inhibitory GABAergic neurotransmission, so any drug effective against PTZ model is said to possibly exert its anticonvulsant action through GABA receptor. ${ }^{10}$ Anticonvulsant activity in PTZ model identifies the compound that can raise seizure threshold in brain. ${ }^{11}$ Antagonism of PTZ induced seizure also indicates that extract of Moringa oleifera has interaction with GABAergic neurotransmission as PTZ interact with GABA Receptor specifically GABA $_{A}{ }^{12}$ Previous studies have shown that flavonoids may cause facilitation of GABAergic systems. ${ }^{13}$ Phytochemical studies have showed the presence of Flavonoids in the ethanolic extract of Moringa Oleifera. Therefore, the probable anticonvulsant activity of MO could be due to flavanoids facilitating GABAergic transmission.

Reduction in duration of hind limb extensor phase and delay in the latency of seizure are considered as important parameters to assess the efficacy of anticonvulsant agents. Tonic hind limb extension is a universal feature of maximum electroshock model in Mice, rats, rabbits, cats, monkeys and humans. Abolition of Tonic Hind limb extension in MES test predicts the ability of drug to prevent the spread of seizure discharge from epileptic focus and its effectiveness in MES test correlates well in suppressing generalized tonic clonic seizure. ${ }^{14,15}$

The ethanolic extract of MO was not able to abolish Tonic hind limb extension at all doses used in the study but significantly reduced its duration. With respect to PTZ model, the test drug at both the doses delayed the onset of clonic seizures when compared to control. On comparing the percentage protection offered by Moringa oleifera leaves against both MES and PTZ model, it possesses significant anticonvulsant activity at both doses, with more efficacy at $300 \mathrm{mg} / \mathrm{kg} \mathrm{BW}$ indicating that the test drug can prove a very promising drug for treatment of epilepsy.

\section{CONCLUSION}

The ethanolic extract of Moringa oleifera leaves produced significant anticonvulsant activity in animal models. The flavanoids present in the extract could be the main phytoconstituent contributing to its anticonvulsant activity. Further studies are required to determine the exact mechanism of anticonvulsant action of Moringa oleifera.

\section{ACKNOWLEDGEMENTS}

Authors would like to thank Dr. Niraj Jain, Dr. Alok Pandey, for his support during study.

Funding: No funding sources

Conflict of interest: None declared

Ethical approval: The study was approved by the Institutional Ethics Committee

\section{REFERENCES}

1. Sridharan R, Murthy BN. Prevalence and pattern of epilepsy in India. Epilepsia. 1999;40(5):631-6. 
2. Kamboj P, Singh I, Mahadevan N, Chaudhary G. Anticonvulsant from nature. Phcog Rev. 2009;108-17. Available at: www.Phcogrev.com.

3. Roy MK, Das D. Indian Guidelines on epilepsy. IAP expert committee guidelines. 528-32.

4. Jayaram R, Anitha T, Joshi VD. Analgesic and anticonvulsant effects of Acoruscalamus roots in mice. International Journal of Pharma Tech Research. 2010;2(1):552-5.

5. Kesharwani S, Prasad P, Roy A, Sahu RK. An overview on Phytochemistry and Pharmacological Exploration of Moringa Oleifera. UK Journal of Pharmaceutical and Biosciences. 2014;2(1):34-41.

6. Farooq A, Latif S, Muhammad A, Gilani AH. Moringaoleifera: A Food Plant with Multiple Medicinal Uses. Phytotherapy Research. 2007;(21):17-25.

7. Goyal BR, Agrawal BB, Goyal RK, Mehta AA. Phytopharmacology of Moringaoleifera lam an overview. Natural Product Radiance. 2007;6(4):34753.

8. Gantara TH, Joshi UH, Bhalodia PN, Desai TR, Tirgar PR. A panoramic view of pharmacognostic, pharmacological, nutritional, therapeutic and prophylactic values of Moringaoleifera Lam. International Research Journal of Pharmacy. 2012;3(6):1-7.

9. Mc Namara JO, Hardman JG, Limbird JE, Molioff PB, Ruddon RW, Gillman AG. Drugs effective in the treatment of epilepsies. Goodman and Gillman s The Pharmacological basis of Therapeutics.12th edition. NewYork: Mc Graw Hill; 2012:583-586.

10. Muhammad R, Abdullah A, Alghasham, Mohammad SA. Potentation of valporate induced anticonvulsant response by Nigella sativaseed constituents -The role of GABA receptor. International Journal of Health sciences. 2008;2(1):15-25.

11. Raza M, Saheen F, Choudhary MI, Sombati S, Rafiq A, Suria A, et al. Anticonvulsant activities of ethanolic extract and aqueous fraction isolated from delphinium denudatum. J Ethnopharmacol. 2001;78(1):73-8.

12. De Sarro A, Cecchetti V, Frarolini V, Naccari F, Tabarrini O, De Sarro G. Effect of novel 6desfluoroquinolones and classic quinolones on pentylenetetrazole induced seizure in mice. Antimicrob agents. Chemother. 1999;43:1729-36.

13. Fernandez SP, Wasowski C, Loscalzo LM, Granger RE, Gohnston GA, Paladini AC, et al. Central nervous system depressant action of flavonoid glycosides. Eur J Pharmacol. 2006;539:168-76.

14. Krall RL, Penry JK, White BG, Kuferberg HJ, Swinyar Eug A. Antiepileptic drug development II. Anticonvulsant Drug screening. Epilepsia. 1978;19(4):409-28.

15. Porter RJ, Cereghino JJ, Gladding GD, Hessie BJ, Kupferberg HJ, Scoville B, et al. Antiepiletic Drug Development program. Cleve clinQ. 1984;51(2):293305.

Cite this article as: Naidu SV, Harsha R, Jyothsnya $\mathrm{S}$. To evaluate the anticonvulsant activity of ethanolic extract of Moringa oleifera (drumstick leaves) in albino mice. Int J Basic Clin Pharmacol 2017;6:2491-5. 